\title{
Systems pathology-or how to solve the complex problem of predictive pathology
}

\author{
Manfred Dietel • Reinhold Schäfer
}

Published online: 23 December 2008

(C) Springer-Verlag 2008

Erratum to: Virchows Arch

DOI 10.1007/s00428-008-0656-Z

Both Fig. $1 \mathrm{~b}$ and the legend of Fig. 1 were incorrect.

The correct figure and legend are given here.

The online version of the original article can be found at http://dx.doi. org/10.1007/s00428-008-0656-z.

M. Dietel $(\bowtie) \cdot$ R. Schäfer

Department of Pathology, Charité-University Medicine Berlin,

Charitéplatz 1,

10117 Berlin, Germany

e-mail: manfred.dietel@charite.de 
Fig. 1 a "Blind monks examining an elephant" by Itcho Hanabusa (1652-1724 [17]) and b a modern scientist's concept of the "Epidermal growth factor receptor pathway map" [18]. Is there really a fundamental difference between the (re-) searchers at the top and those at the bottom regarding the "objective truth" of the systems?
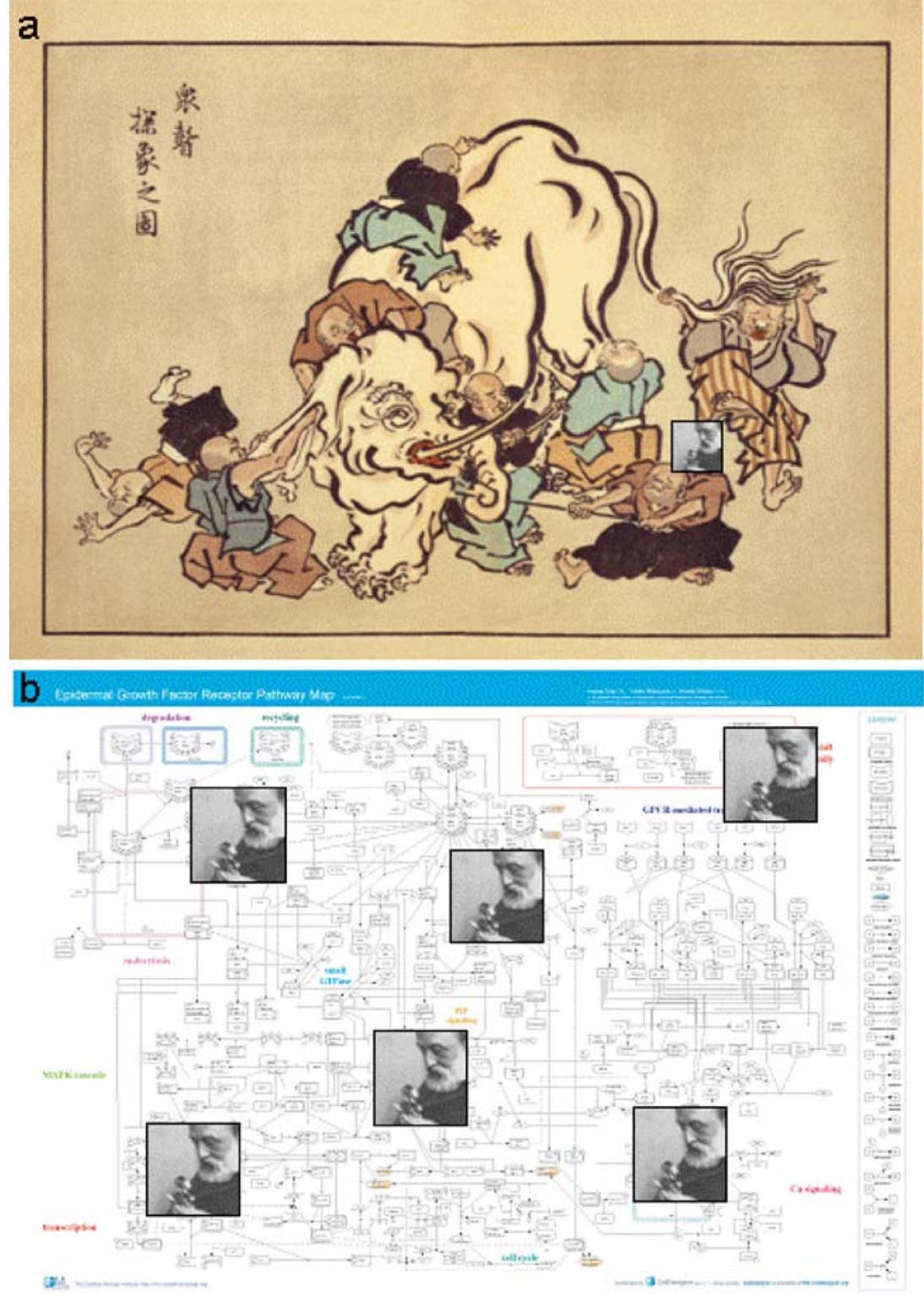